$$
\begin{gathered}
\text { ORNL-3514 } \\
\text { UC- } 25 \text { - Metals, Ceramics, and Materials } \\
\text { TID }-4500 \text { ( } 37 \text { th ed.) }
\end{gathered}
$$

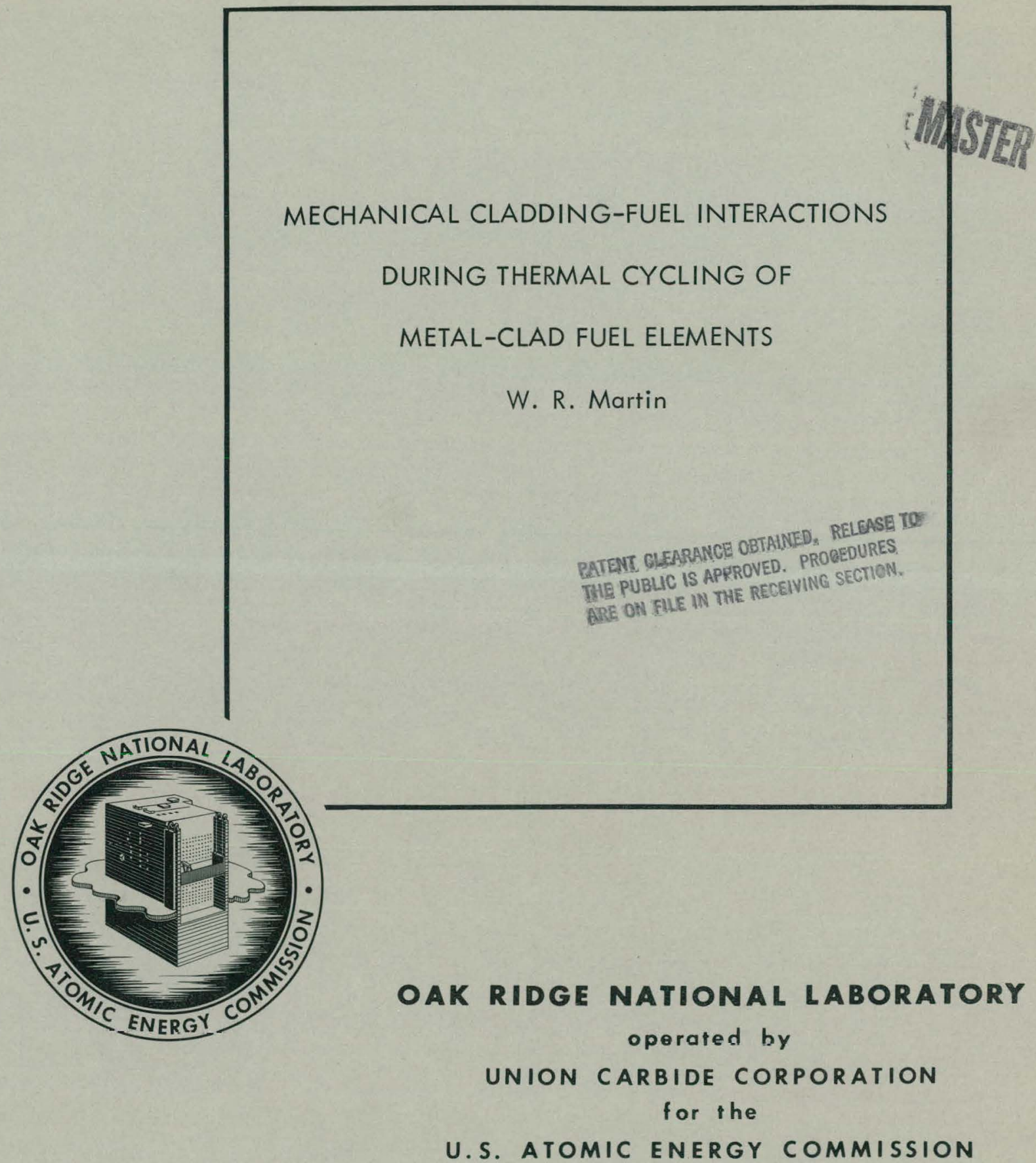




\section{DISCLAIMER}

This report was prepared as an account of work sponsored by an agency of the United States Government. Neither the United States Government nor any agency Thereof, nor any of their employees, makes any warranty, express or implied, or assumes any legal liability or responsibility for the accuracy, completeness, or usefulness of any information, apparatus, product, or process disclosed, or represents that its use would not infringe privately owned rights. Reference herein to any specific commercial product, process, or service by trade name, trademark, manufacturer, or otherwise does not necessarily constitute or imply its endorsement, recommendation, or favoring by the United States Government or any agency thereof. The views and opinions of authors expressed herein do not necessarily state or reflect those of the United States Government or any agency thereof. 


\section{DISCLAIMER}

Portions of this document may be illegible in electronic image products. Images are produced from the best available original document. 
Printed in USA. Price $\$ 2.00$. Available from the Clearinghouse for Federal Scientific and Technical Information, National Bureau of Standards,

U.S. Department of Commerce, Springfield, Virginia

\section{LEGAL NOTICE}

This report was prepared as an account of Government sponsored work. Neither the United States, nor the Commission, nor any person acting on behalf of the Commission:

A. Makes any warranty or representation, expressed or implied, with respect to the accuracy, completeness, or usefulness of the information contained in this report, or that the use of any information, apparatus, method, or process disclosed in this report may not infringe privately owned rights; or

B. Assumes any liabilities with respect to the use of, or for damages resulting from the use of any information, apparatus, method, or process disclosed in this report.

As used in the above, "person acting on behalf of the Commission" includes any employee or contractor of the Commission, or employee of such contractor, to the extent that such employee or contractor of the Commission, or employee of such contractor prepares, disseminates, or provides access to, any information pursuant to his employment or contract with the Commission, or his employment with such contractor. 
ORNL-3514

Contract No. W-7405-eng-26

METALS AND CERAMICS DIVISION

MECHANICAL CLADDING-FUEL INTERACTIONS DURING THERMAL CYCLING OF METAL-CLAD FUEL ELEMENIS

W. R. Martin

MARCH 1965

OAK RIDGE NATIONAL LABORATORY

Oaki Ridge, Tennessee

operated by

UNION CARBIDE CORPORATION

for the

U. S. ATOMIC ENERGY COMMISSION 


\section{FOREWORD}

This réport covers work performed by the Mechanical Properties.

Group of the Metals and Ceramics Division during the period July, 1961 through september, 1963. 
CONTENTS

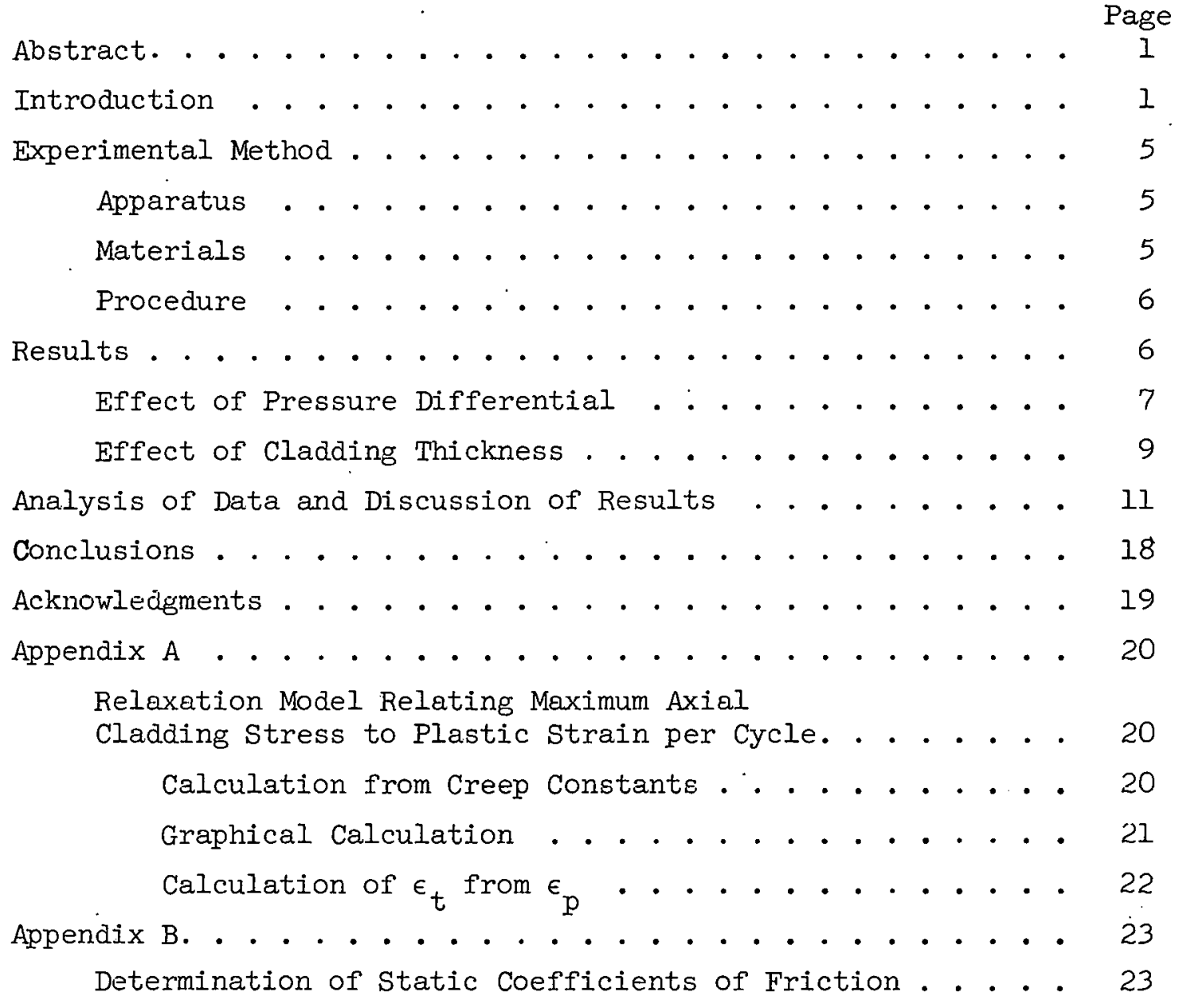




\title{
MECHANICAL CLADDING-FUEL INTERACTIONS DURING THERMAL CYCLING \\ OF METAL-CLAD FUEL ELEMENTS
}

\section{W. R. Martin}

\begin{abstract}
The effect of pressure and cladding thickness on the progressive extension of metal-clad $\mathrm{UO}_{2}$ fuel elements during thermal cycling has been investigated. As a result of the data analysis, a model describing the progressive extension of the fuel elements during cycling is presented. The model describes the importance of contact pressure, coefficient of friction, and material properties as well as number and magnitude of the thermal cycles. The model indicates the ratchetting to be a special case of a lowcycle strain-fatigue problem. Hence, in the absence of ratchetting, cladding failures due to strain fatigue of cladding are also predicted by the mudel.
\end{abstract}

\section{INTRODUCTION}

A criterion for the successful operation of metal-clad fuel elements in reactor systems is that the element be free of metallurgical and mechanical problems that could lead to fracture of the cladding. In fuel elements made up of ceramic fuel pieces, such as stacked pellets; and placed in metal tubing without a metallurgical bond, one of the more serious problems is mechanical interaction between the fuel and the cladding. The interaction contact between the cladding and fuel could be eliminated by selecting a cladding material that would be free standing in the reactor environment. However, for many reactor concepts, an element so designed requires low metal-wall temperatures, coolant pressures below or equal to the pressure inside the can, thick-wall cladding or strong creep resistant cladding material. Any of these choices can adversely affect the power-producing ability and economy of the system. In many cases, a free-standing cladding is not possible under the operating conditions required of the reactor. Since the useful life of a fuel element depends on the ability of the cladding to contain the fuel and the fission products, one needs to understand, evaluate, and. minimize fuel-cladding interactions in fuel elements with cladding that is not free standing. 
Nonfree standing cladding is obtained in several ways. The element can be fabricated with no diametral gap between cladding and fuel. However, to load the pellets into the tubing requires a diametral gap. This gap may be reduced or eliminated during reactor operation either (a) by instantaneous or creep collapse of the cladding about the stack of pellets or (b) by interference due to the fuel expanding diametrically more than the tubing. The method by which the cladding achieves intimate contact with the fuel can by itself cause element failure. Therefore, this method must be known before mechanical interaction of cladding and fuel during thermal cycling is considered a primary cause of element failure.

For example, Fig. I shows an element that failed when the cladding buckled due to excessive diametral clearance. This problem of buckling due to instantaneous collapse of the clad about the fuel is discussed elsewhere. ${ }^{1-5}$

Creep collapse of the cladding about the fuel can produce cladding protrusions (as shown in Fig. 2) that are potential locations for failure. The protrusions are due to degradation of the fuel followed by collapse of the cladding. Circumferential ridging of the cladding at locations corresponding to peliet-to-pellet interfaces has not been shown to cause failure. However, since the cladding is strained at these ridges, they are potential failure sites. The ridges are believed to be the result of the cladding collapsing plastically about the fuel and assuming the

${ }^{1}$ R. G. Sturm, A Study of the Collapsing Pressure of Thin Wall Cylinders, University of Illinois Bulletin, No. 12; Vol.XXXIX, Nov. 11, 1941.

${ }^{2}$ C. R. Kennedy and J. T. Venard, Collapse of Tubes by External Pressure, ORNL-TM-166. (April 17, 1962).

${ }^{3}$ B. E. Murtha and W. P. Chernock, "Collapse Tests," The Development of Testing of $\mathrm{UO}_{2}$ Fuel Systems for Water Reactor Application, CEND-152 (Jan. 1962).

${ }^{4} \mathrm{~J}$. P. Ellington, Creep Collapse of Tubes Under External Pressure, DEG-162R (1960).

5 J. P. 'Ellington, Creep Stability of Tubes Under External Pressure, DEG-234R (1960). 


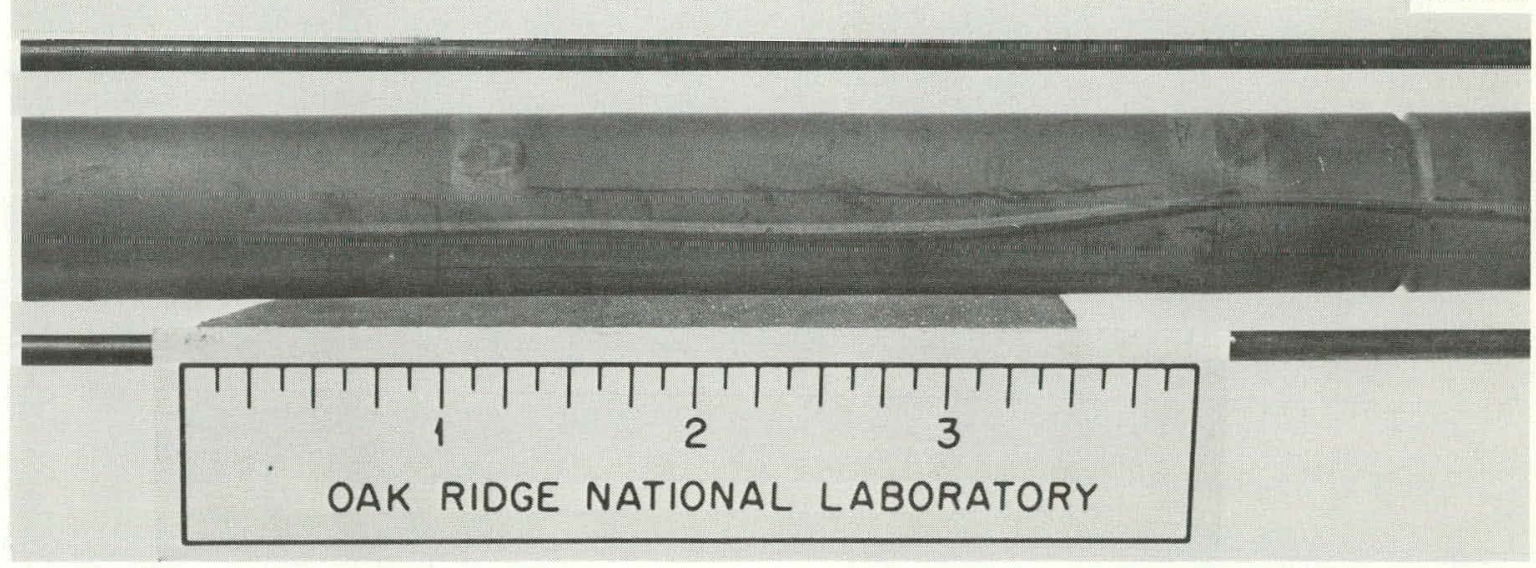

Fig. 1. Failure from Buckling Due to Excessive Clearance.

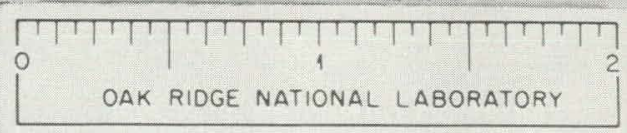

Fig. 2. Cladding Protrusions Formed by Creep Collapse. 
shape profile of the pellets. If the diametral expansion of the fuel results in a strain exceeding the fracture strain of the cladding the element failure is immediate. These sources of failure must be eliminated before the problem of mechanical interaction during thermal cycling is considered.

Cycling of a fuel element with nonfree standing cladding can produce ratchetting. The specific type of thermal ratchetting of interest here results in separation of fuel pellets within a stack, accompanied by axial plastic flow of the cladding. The cause of ratchetting is not well understood, but certainly fuel elements in normal use will be thermally cycled, and failure due to ratchetting is possible. Hence, the phenomenon of ratchetting of metal-clad fuel elements during thermal cycling has been examined by several investigators.

our previous investigations ${ }^{6}$ disclosed that the axial plastic deformation found in the 0.020-in.-thick stainless steel cladding of thermally cycled fuel elements was in part due to creep. The magnitude of the plastic strain per cycle increased with increasing cladding temperature and increasing magnitude of the thermal cycles. However, in irradiation experiments by Lyons ${ }^{7}$ and Spalaris, ${ }^{8}$ the strain in aluminumor stainless steel-clad rods after cycling was related to the yield stress of the cladding material and due to thermal expansion of the fuel. These investigators have also reported that no relative movement of cladding and fuel occurred during thermal cycling. These irradiation results contrast with those reported by Notley, ${ }^{9}$ who tested elements made up of uranium dioxide fuel pellets in both thin- and thick-wall zircaloy sheaths under high pressure differentials. His results indicated that

${ }^{6}$ W. R. Martin and J. R. Weir, Dimensional Behavior of the Experimental Gas-Cooled Reactor Fuel Element at Elevatcd Temperatures, ORNL-3103 (1961).

${ }^{7}$ M. F. Lyons et al., Plastic Strain in Thin Fuel Element Cladding Due to $\mathrm{UO}_{2}$ Thermal Expansion, GEAP-3739 (1961).

${ }^{8}$ C. N. Spalaris, "Uranium Dioxide-Cladding Interactions. Axial Expansion of $\mathrm{UO}_{2}$ Column in Fuel Elements," Nucl. Sci. Eng. 17(3), 381-392 (Nov. 1963).

${ }^{9}$ M. J. F. Notley, The Relative Axial Expansions Under Irradiation of Stacks of $\mathrm{UO}_{2}$ Pellets in Zircaloy Sheaths, AECL-1598 (1962). 
the cladding did plastically deform and that the relative movement of the cladding and fuel depended upon the coolant pressure.

There are many aspects of these and other experiments that are in accord. First, the mechanical strain imparted to the cladding is related to the difference in the expansion of the fuel body and cladding.

Second, the fuel must contact the cladding before the cladding can deform. On the other hand, the amount of relative movement of cladding and fuel appears to differ for different element configurations and test conditions.

Plastic cladding strains are apparently due to the difference in thermal expansion of cladding and fuel exceeding the relative movement of the two bodies. One purpose of this investigation was to examine the influence of cladding thickness and pressure difference across the cladding on axial ratchetting. Secondly we anticipated that the data generated might be analyzed to give an improved model for ratchetting from which methods for reducing the ratchetting might be derived and applied to fuel element design.

EXPERTMENTAL METHOD

Apparatus

The experimental apparatus has been described in detail previously. 10 We stacked annular pellets of uranium dioxide into tubing of the cladding material under investigation and then assembled them into a rig that provided a central tantalum heating rod, a cooled outer pressure jacket, and an extensometer to measure and automatically record changes in length of a 10-in. section of fueled tubing.

\section{Materials}

We tested three heats of 0.710-in. ID tubular type 304 stainless steel. The chemical analyses of these heats are given in Table 1. Tubing of heat 94489 had wall thicknesses of $0.005,0.010$, and 0.015 in. Tubing of the other heats had 0.020-i.n. walls.

$10 \mathrm{~W} . \mathrm{R}$. Martin and J. R. Weir, A Device to Simulate the service Thermal Conditions in EGCR Type Fuel Elements, ORNL-3032 (Dec. 28, 1960 ). 
Table 1. Chemical Analyses of Stainless Tubing

\begin{tabular}{lccc}
\hline Element & \multicolumn{3}{c}{ Wt \% for Each Heat Number } \\
\cline { 2 - 4 } & 94489 & $23999 \mathrm{X}$ & 23478 \\
\hline C & 0.04 & 0.05 & 0.011 \\
Cr & 18.02 & 18.92 & 18.3 \\
Ni & 9.44 & 10.39 & 10.4 \\
Mn & 1.68 & 1.61 & 1.00 \\
S & 0.006 & 0.006 & 0.014 \\
P & 0.027 & 0.016 & 0.002 \\
Si & 0.47 & 0.38 & 0.54 \\
Mo & & & 0.02 \\
Cu & & & 0.09 \\
\hline
\end{tabular}

avacum-melted stainless heat.

The uranium dioxide pellets used were $95 \%$ of theoretical density and had been sintered at $2900^{\circ} \mathrm{F}$ in hydrogen. They were 0.708 -in. diam $\times 0.75$-in. long.

\section{Procedure}

The axial. extensions of the cladding tubing were recorded as a function of time in two sets of experiments. In each set the fuel elements were cycled between identical upper and lower temperature limits, using the same heating and cooling rates. In the first set, the cladding thickness was varied, with the pressure differential kept constant at $300 \pm 15 \mathrm{psi}$. In the second, the pressure differential and time at temperature were varied for 0.020-in.-thick tubing. Data from the two sets are not intercomparable, since modifications to the apparatus between sets altered the thermal cycle.

\section{RESULTS}

During a thermal cycle, a complex variation occurs in the length of the cladding. During heating the length increases sharply, partly due to thermal expansion and partly due to strain from the cladding being dragged 
by the expanding fuel pellets. The fuel expands more than the cladding, despite its smaller coefficient of thermal expansion, because of its much greater temperature change. This increase may be partly diminished by slippage, in some cases diminishing as the cladding reaches temperature and expands away from the fuel. Finally, during cooling the length decreases, either restoring the original length or leaving a residual strain depending on whether the strain had been purely elastic or partly plastic.

\section{Effect of Pressure Differential}

Data on the effect of differential pressure and time at temperature on the elongation of the cladding during thermal cycling are given in Table 2. Under the conditions of these experiments, the plastic strain per cycle increased with increasing pressure. Fig. 3. gives the extension as a function of time for one cycle at each pressure. The figure shows clearly that the total strain increases with the differential pressure. However, since the extension includes thermal expansion, the absolute magnitude of the strain may not be inferred without additional assumptions; the figure shows a calculation neglecting the strain at the lowest pressure.

Further interpretation of the data is possible with the aid of tensile and creep properties of the tubing material. In what appears to be a reasonable model of the deformation process, one assumes that at the beginning of the cycle the tubing is elastically and possibly plastically deformed, corresponding to an initial stress $\sigma_{0}$. As the element is maintained at temperature, relaxation occurs and some of the elastic strain becomes plastic. The calculation relating the initial stress, the total plastic strain, and the mechanical properties of the material is described in Appendix $A$, and values of the initial stress thus derived are included in Table 2. In turn the total strain $\epsilon_{t}$ can be calculated using the empirical. stress-strain curve (Fig. 6, Appendix A). In Table 2, these values show good agreement with observed values obtained by assuming the graphical value for the low pressure and using the differences derived from Fig. 3. Finally, the slippage between the fuel and cladding 
Table 2. Flastic Straining of Cladding For Fuel Element Cycled at Various Pressures

Thermal Conditions: Cladding temperature limits, $1475^{\circ} \mathrm{F}$ to $425^{\circ} \mathrm{F}$

Central fuel temperature limits, $2420^{\circ} \mathrm{F}$ to $640^{\circ} \mathrm{F}$ Average heating rate, $170^{\circ} \mathrm{F} / \mathrm{min}$

\begin{tabular}{|c|c|c|c|c|c|c|c|}
\hline \multirow{2}{*}{$\begin{array}{l}\text { Coolant } \\
\text { Pressure } \\
\quad \text { (psi) }\end{array}$} & \multirow{2}{*}{$\begin{array}{l}\text { Observed Plastic } \\
\text { Strain per Cycle } \\
\left(\epsilon_{\mathrm{p}}\right)\end{array}$} & \multicolumn{2}{|c|}{$\begin{array}{c}\text { Cycling Times } \\
(\mathrm{hr})\end{array}$} & \multirow{2}{*}{$\begin{array}{l}\text { Initial } \\
\text { Stress, } \\
\left(\sigma_{0}\right) \\
\text { Calculated } \\
\quad \text { (psi) }\end{array}$} & \multicolumn{2}{|c|}{$\begin{array}{l}\text { Comparison of Total } \\
\text { Strain Introduced } \\
\text { into Clad by Fuel }\end{array}$} & \multirow{2}{*}{$\begin{array}{l}\text { Observed Relative } \\
\text { Movement of } \\
\text { Cladding and Fuel } \\
\text { (Slippage } \epsilon_{\mathrm{s}} \text { ) }\end{array}$} \\
\hline & & Heating $^{a}$ & Cooling & & Graphically $^{c}$ & Observed $^{\mathrm{d}}$ & \\
\hline & & & & & $\times 10^{-4}$ & $\times 10^{-4}$ & $\times 10^{-4}$ \\
\hline 300 & $4.0 \times 10^{-4}$ & 0.5 & 0.5 & 11,900 & 24.0 & 21.5 & 0 \\
\hline 200 & $2.5 \times 10^{-4}$ & 0.5 & 0.5 & 9,500 & 14.0 & 16.0 & 5.5 \\
\hline 100 & $\begin{array}{l}\text { None observed } \\
<1 \times 10^{-5}\end{array}$ & 0.5 & 0.5 & & & 3.5 & 18.0 \\
\hline 100 & $1.0 \times 10^{-4}$ & 1.5 & 0.5 & 5,400 & 3.5 & 3.5 & 18.0 \\
\hline
\end{tabular}

$a_{\text {including time at temperature }}$

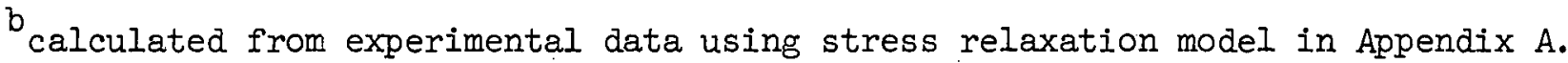

c determined from tensile stress-strain curve of type 304 stainless steel. (see Fig. 6, Appendix A).

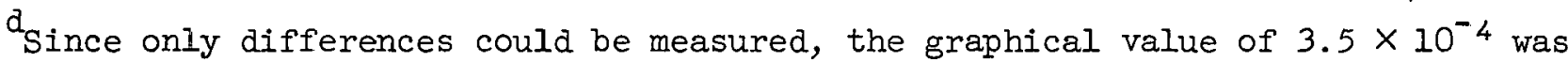
assumed for $100 \mathrm{psi}$, and the other values in this column were derived from this by adding the cbserved differences. 


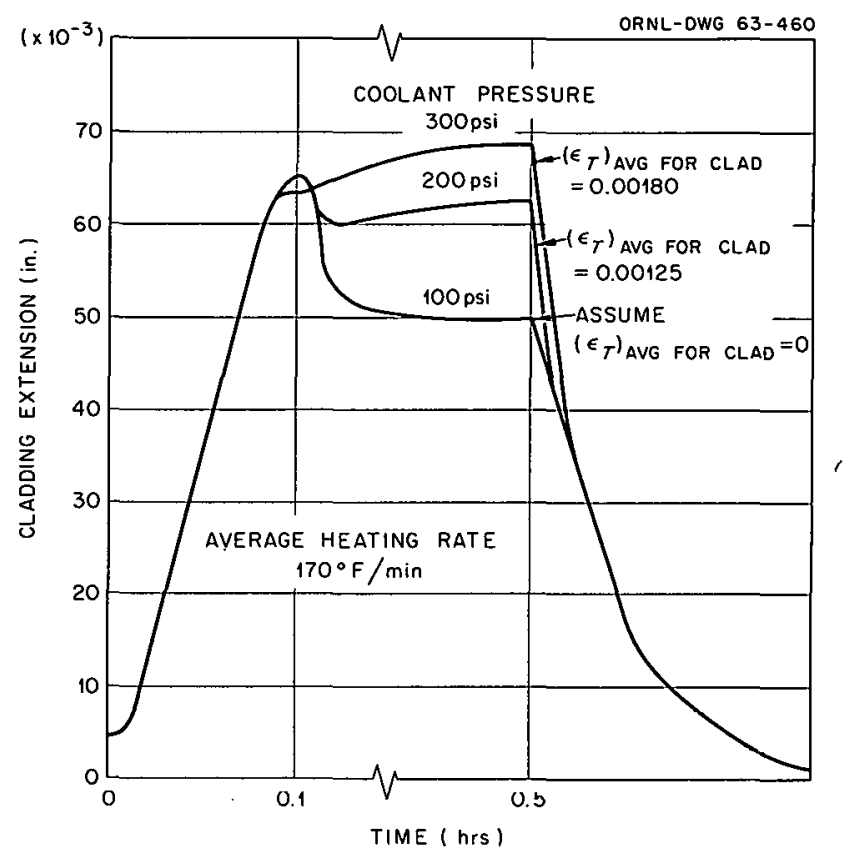

Fig. 3. Extension Behavior of 10-in. Stainless Steel Clad-UO $\mathrm{U}_{2}$ Fuel Element During One Thermal Cycle for Various Coolant Pressures.

can be calculated from the total strains if one assumes negligible slippage at the high differential pressure.

We can see in Table 2 that increasing the time at temperature can result in ratchetting for conditions at which no ratchetting is observed when the heating time is short. In this case, the stress appears to be so small that negligible relaxation occurs in the shorter period, but on prolonged heating the amount of relaxation becomes measurable.

\section{Effect of Cladding Thickness}

The effect of cladding thickness on the plastic strain per cycle is shown in Fig. 4. These results show an unanticipated increase in the plastic strain with decreasing cladding thickness. As before, the maximum (or initial) axial stress in the cladding $\sigma_{0}$ may be computed using the stress relaxation wodel in Appendix A. These values of $\sigma_{0}$, given in Table 3, decrease with increasing cladding thickness. Multiplying these stresses by the cross-section area $A_{0}$ of the cladding gives the maximum load $L_{0}$, which is also shown in Table 3 and increases with increasing cladding-wall thickness. If the initial cladding strain depended only 
on the thermal expansion of the fuel and cladding, the plastic strain per cycle would not have varied with cladding thickness, and the calculated stress $\sigma_{0}$ would have been constant.

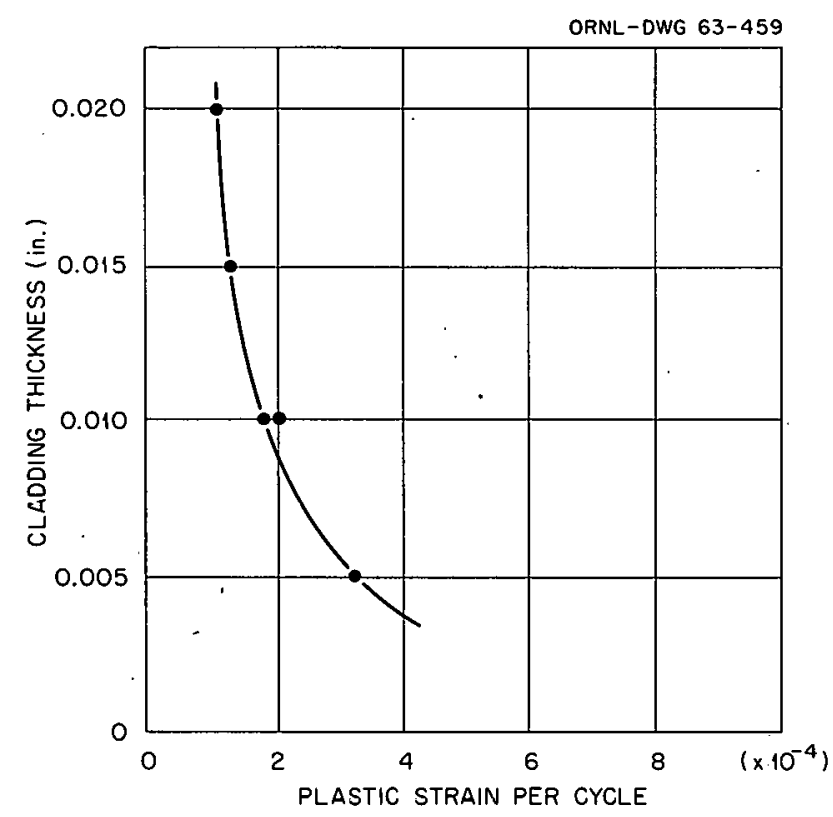

Fig. 4. Axial Plastic Strain Per Cycle for Metal-Clad Elements with Cladding Thickness as a Variable. Cladding was cycled between the temperature limits of $1475^{\circ} \mathrm{F}$ and $500^{\circ} \mathrm{F}$. Respective fuel temperatures were $2500^{\circ} \mathrm{F}$ and $550^{\circ} \mathrm{F}$.

Table 3. Maximum Stress and Force as a Function of Cladding Thickness

\begin{tabular}{cccc}
\hline $\begin{array}{c}\text { Cladding Thickness } \\
\text { (In.) }\end{array}$ & $\begin{array}{c}\text { Calculated } \\
\sigma_{0} \\
(p s i)\end{array}$ & $\begin{array}{c}\text { Calculated } \\
L_{0}=A_{0} \sigma_{0} \\
(1 \mathrm{~b})\end{array}$ & $\begin{array}{c}\text { Observed Slippage } \\
\epsilon_{\mathrm{s}}\end{array}$ \\
\hline 0.005 & 13,100 & 147 & 0 \\
0.010 & 10,500 & 250 & 0.006 \\
0.015 & 8,800 & 340 & 0.001 \\
0.020 & 8,700 & 350 & 0.001 \\
\hline
\end{tabular}


ANALYSIS OF DATA AND DISCUSSION OF RESULTS

A detailed comparison of the results of these experiments with previous data is in order. First, the proposal that the ratchetting is due to fuel expansion is true. However, the magnitude of the strain in the cladding is not a function of fuel expansion only. The strain imparted to the cladding would be the difference in the thermal expansion of cladding and fuel if no slippage occurred. However, since relative movement of cladding and fuel can occur, the magnitude of the total strain in the cladding can be expressed as:

$$
\epsilon_{t}=\left(\epsilon_{\mathrm{f}}-\epsilon_{\mathrm{c}}\right)-\epsilon_{\mathrm{s}}
$$

where

$\epsilon_{t}=$ total strain in cladding (not including thermal expansion), $\epsilon_{f}=$ thermal expansion of fuel,

$\epsilon_{\mathrm{c}}=$ thermal expansion of cladding, and

$\epsilon_{\mathrm{S}}=$ slippage or relative movement.

Since $\left(\epsilon_{f}-\epsilon_{c}\right)$ can not be a tunction of pressure, the variation of total cladding strain $\epsilon_{t}$ was due to a variation of the slippage. As seen in Table 2 , this quantity increased with decreasing pressure. When $\epsilon_{\mathrm{S}}$ is zero, $\epsilon_{t}$ is as great as possible for a given $\left(\epsilon_{f}-\epsilon_{c}\right)$. Recognize that $\epsilon_{t}$ is also the sum of the elastic and plastic strains in the cladding. When the total cladding strain exceeds the elastic strain limit of the clading, plastic straining occurs, and the magnitude of ratchetting would be related to the yield strength of the material as suggested by Lyons. ${ }^{11}$ However, if the total initial strain is essentially only elastic and therefore recoverable, the temperature of the cladding must be high enough so that the process of stress relaxation can occur before any plastic strain will be observed. Thus, our observation and Lyons' are compatible.

Therefore, the difference in thermal expansion $\left(\epsilon_{f}-\epsilon_{c}\right)$ must either be minimized or balanced by the slippage $\epsilon_{s}$ to eliminate plastic straining

${ }^{1{ }^{1}}$ M. F. Lyons et al., Plastic Strain in Thin Fuel Element Cladding Due to $\mathrm{UO}_{2}$ Thermal Expansion, GEAP-3739 (1961). 
of the cladding. Relative movement of cladding and fuel can occur if the frictional forces between them are low. The maximum frictional force is given by:

$$
F_{0}=\mu_{s} F_{n}
$$

where

$$
\begin{aligned}
F_{0}= & \text { maximum frictional force (longitudinal shearing force at } \\
& \text { cladding-fuel interface), } \\
\mu_{\mathrm{S}}= & \text { static coefficient of friction, and } \\
F_{\mathrm{n}}= & \text { contact force acting normal to the cladding-fuel contact } \\
& \text { surface, (equal to pressure times area). }
\end{aligned}
$$

Values of the coefficient of friction between $\mathrm{UO}_{2}$ and stainless steel as a function of $F_{n}$ are not yet available. However, data at very low values of $F_{n}$ indicate the magnitude of $\mu_{S}$ to be within the range of 0.3 to 1.4 for temperatures between 70 and $1800^{\circ} \mathrm{F}$ (See Appendix B).

The tensile load on the cladding $A_{0} \sigma_{0}$ or $L$ cannot exceed the maximum frictional force. Once the tensile load becomes equal to the frictional force, relative movement occurs between cladding and fuel and the load can increase no further. Table 4 shows the maximum load $\mathrm{L}_{0}$ calculated for the tests in which pressure was varied. Those values for tests in which slippage occurred must be equal to the maximum frictional force; indeed, they are nearly proportional to the pressure differential, which is the primary contributor to the contact force if the cladding behaves as a plastic envelope. Assuming this to be the case, the con-. tact force $F_{n}$ is calculated from:

$$
F_{n}=\pi d_{1} l P
$$

where

$$
\begin{aligned}
& \mathrm{d}_{1}=\text { inside diameter of the cladding, } \\
& \mathrm{P}=\text { pressure differential, and } \\
& \boldsymbol{l}=\text { effective length. }
\end{aligned}
$$

An additional term would have to be added if the cladding restrained the diametral expansion of the fuel. However, with the use of a reasonable value of $\mu_{S}$, the pressure data given in Table 4 correlate without using this interference-fit term. The effective length $\ell$ in the calculation of $F_{n}$ would be the entire length of the element before gaps become 
established at the pellet-to-pellet interfaces. After these gaps are formed, the effective length becomes the length of the pellet, as each pellet moves independently of its neighbor. If transverse cracks develop sufficiently to fracture the pellet into two separate parts and those halves move independently of one another, the effective length would be the average length of those parts. If the fracture of the fuel becomes so severe that the gaps at pellet-to-pellet interfaces are filled with fuel particulates and the pellets or pellet segments no longer move independently of one another, the effective length becomes once again the length of the element. The net result is that the maximum frictional force may change during the test.

Table 4. Comparison of Calculated and Experimental Frictional Forces

\begin{tabular}{ccccc}
\hline $\begin{array}{c}\text { Pressure } \\
(\mathrm{psi})\end{array}$ & $\begin{array}{c}\text { Observed value } \\
\text { of } \mathrm{L}_{0} \\
(1 \mathrm{~b})\end{array}$ & $\begin{array}{c}\text { Calculated } \\
\text { Contact } \\
\text { Force } \mathrm{F}_{\mathrm{n}} \\
(\mathrm{Ib})\end{array}$ & $\begin{array}{c}\text { Calculated } \\
\text { Frictional } \\
\text { Force Fo } \\
(1 \mathrm{~b})\end{array}$ & $\begin{array}{c}\text { Observed } \\
\text { Relative } \\
\text { Movement of } \\
\text { Cladding and } \\
\text { Fuel }\end{array}$ \\
\hline 100 & 235 & 176 & 211 & Yes \\
200 & 435 & 350 & 420 & Yes \\
300 & 520 & 530 & 640 & No \\
\hline
\end{tabular}

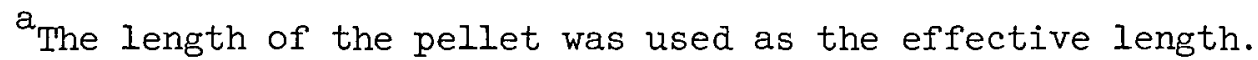

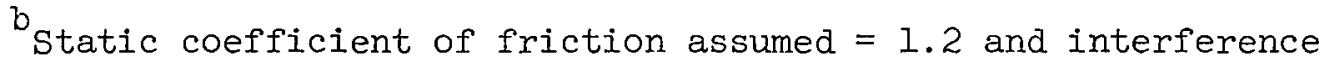
force due to rcatraint of fucl by cladding neglected.

The question of whether the cladding acts as a plastic envelope is pertinent to the analysis and discussion of the effect of cladding thickness. First, if the frictional force during the heating cycle is large and the cladding offers no restraint to the diametral expansion of the fuel, the plastic strain per cycle will not depend on cladding thickness. However, the data in Table 3 show the plastic strain per cycle increasing with decreasing thickness of the cladding. If the heavier wall cladding restrained the diametral expansion, the increased contact pressure would increase the frictional force and thus decrease the slippage. This in 
turn would lead to a greater total strain and hence a greater plastic strain than in the thinner cladding. The opposite was observed. Hence, we believe that neither the 0.005- nor 0.020-in. -wall cladding significantly restrained the diametral expansion of the fuel.

The increased plastic deformation of the cladding with decreasing thickness could be explained partially if the frictional force was lower than that observed for the tests in which pressure was varied. This is a good possibility, since some relative movement was observed for the experiments with heavier wall tubes. If a lower frictional force were the only reason for the observed behavior, one would expect the maximum stress $\sigma_{0}$ to be constant for tubes of sufficient wall thickness; this appeared to be the case for 0.015 - and 0.020-in. walls in those experiments. One cannot, however, explain the difference in results for the 0.005- and 0.020-in. walls as due to this phenomenon unless the frictional forces are a function of wall thickness.

The effect of cladding thickness on plastic strain appears best explained in terms of restraint of the thermal expansion of the fuel. As the thermal expansion of the fuel causes a tensile force on the cladding, in reaction an equal compressive force is exerted on the fuel pellets. The magnitude of this force and thus of the compressive stress on the fuel obviously increases with cladding thickness. For the thicker cladding, this stress could be great enough to cause elastic strains near $1 \times 10^{-4}$, an amount significant compared to the cladding strain. This fuel strain would thus result in a decrease in the observed plastic cladding strain with increasing wall thickness.

If the fuel did not deform elastically, the plastic strain per cycle and hence the calculated initial stress would be the same for elements with all cladding thicknesses. Since there is an obvious difference in initial stress for the extreme thicknesses, the fuel with the thicker cladding undoubtedly deforms. This can be verified by calculating, from the measured plastic strain per cycle, what the maximum initial stress $\sigma_{0}$ of both 0.005- and 0.020-in. wall tubes would have been if the fuel had not been elastically compressed. We can calculate this in straightforward steps. The compressive force on the fuel is equal to the tensile force $\mathrm{L}_{0}$ 
on the cladding given in Table 3. From this and the dimensions of the fuel, we obtain the compressive stress. Using an elastic modulus of $25 \times 10^{6}$ psi for the fuel, from Hooke's law we obtain the strain in the fuel. Adding this to the observed total cladding strain, we find what the total strain would have been if the fuel had not been strained. From these values by the method of Appendix A, the initial stress values 13,800 and 14,700 psi are found for the 0.020- and 0.005-in. claddings respectively. This is sufficiently good agreement to indicate that the difference in plastic strain behavior of cladding with different thicknesses is due to the compression of the fuel.

Therefore, it seems reasonable that the slippage term must include not only the relative movement due to loads in excess of the frictional force but also the reduction in total strain due to the compression of the fuel. Hence:

$$
\epsilon_{s}=\epsilon_{s_{1}}+\epsilon_{s_{2}}
$$

where

$\begin{aligned} \epsilon_{\varepsilon_{I}} & =\begin{array}{l}\text { slippage due to forces equal to or in excess of the trictional } \\ \text { force, and }\end{array}\end{aligned}$

$\epsilon_{S_{2}}=$ a reduction in total strain due to fuel compressive strains. The values of $\epsilon_{\mathrm{S}_{1}}$ and $\epsilon_{\mathrm{S}_{2}}$ are dependent upon the magnitude of the tensile load in the cladding relative to the frictional force and the relationship of stress and strain for the cladding material. The calculation of $\epsilon_{s_{1}}$ and $\epsilon_{s 2}$ could be simplified by establishing special cases.

The model for straining of the cladding is one in which the cladding is strained due to the difference in thermal expansion of fuel and cladding whenever the cladding is in contact with fuel. The magnitude of strain is dependent upon a number of factors, all discussed previously, but no explanation has been given for why the ratchetting continues with cycling. The process of ratchetting that results in cladding extending progressively in each cycle is due to a difference in the relative movement during heating and cooling. All that is required for progressive extension of the cladding with each thermal cycle is for the magnitude of relative movement, $\epsilon_{S}$, to be greater on the cooling cycle than on the heating cycle. If $\epsilon_{s}$ is constant but not equal to $\left(\epsilon_{f}-\epsilon_{c}\right)$, the strains are reversed each cycle and although no progressive extension is observed, 
the cladding is strain cycled. Close analysis of the strain-time curves for elements cycled out-of-reactor clearly demonstrates that $\epsilon_{\mathrm{s}}$ is greater on cooling than heating, which results in ratchetting. The phenomenon of thermal ratchetting of fuel elements can be classified with respect to degree of slippage during cycling. The classes are shown in Table 5. One can construct load-extension curves for all classes from experiments simulating reactor conditions, such as experiments using the internal heater device and those experiments in which an element is cycled from one isothermal level to another. Fig. 5 shows those plots for classes $1 A, I B$, and $1 \mathrm{C}$ as applicable to the internal heater device and reactor operation for elements in which the expansion of fuel exceeds the expansion of cladding. Progressive ratchetting is but a special case of the low-cycle strain-fatigue problem.

Curves describing the cladding-fuel interaction of low-heat-rating fuel elements, for example those in which the expansion of cladding exceeds the expansion of the fuel, are similar. For the low-heat-rating elements, however, fast cooling rates and collapse of the cladding at full power result in the cladding being strained in tension during cooling rather than during the heating portion of the cycle as was noted for the

Table 5. Classification of Fuel Elements with Respect to Degree of Slippage During Thermal Cycling

\begin{tabular}{|c|c|c|}
\hline & Characteristics of Class & During Thermal Cycling \\
\hline Class No. & Heating Portion & Cooling Portion \\
\hline IA & No relative movement & Same as heating cycle \\
\hline $1 B$ & No relative movement & Partial relative movement \\
\hline IC & No relative movement & Complete relative movement \\
\hline $2 \mathrm{~A}$ & Partial relative movement & No relative movement \\
\hline $2 \mathrm{~B}$ & Partial relative movement & Same as heating cycle \\
\hline $2 \mathrm{C}$ & Partial relative movement & Complete relative movement \\
\hline $3 A$ & Complete relative movement & No relative movement \\
\hline $3 B$ & Complete relative movement & Partial relative movement \\
\hline $3 c$ & Complete relative movement & Same as heating cycle \\
\hline
\end{tabular}


high-heat-rating elements. Hence no relaxation of tensile forces is observed for the low power elements except for small cycling ranges and long hold times at the lower temperature level. The criterion for progressive ratchetting of these low-power-rated elements is that the relative movement $\epsilon_{\mathrm{S}}$ be greater during heating than on cooling.

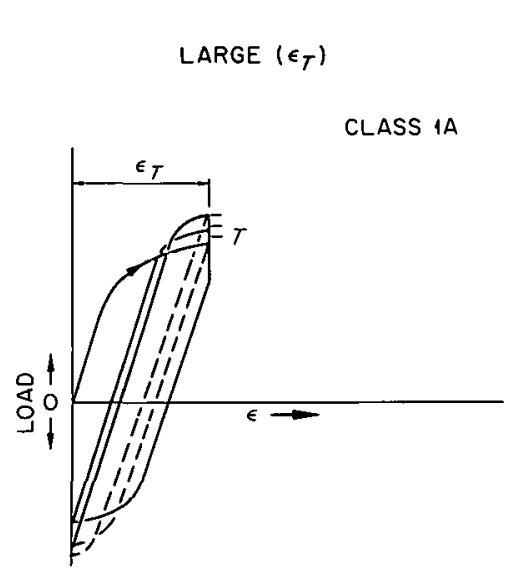

ORNL-OWG $63-461$

SMALL $\left(\epsilon_{T}\right)$

$\epsilon_{T}<$ ELASTIC LIMIT

CLASS 1B
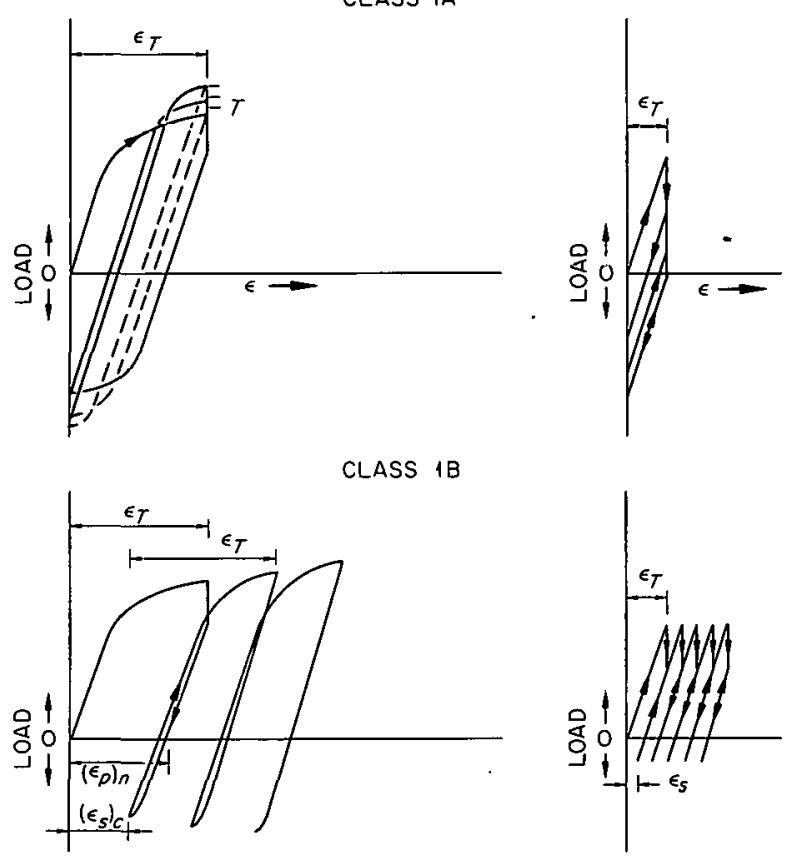

CLASS IC
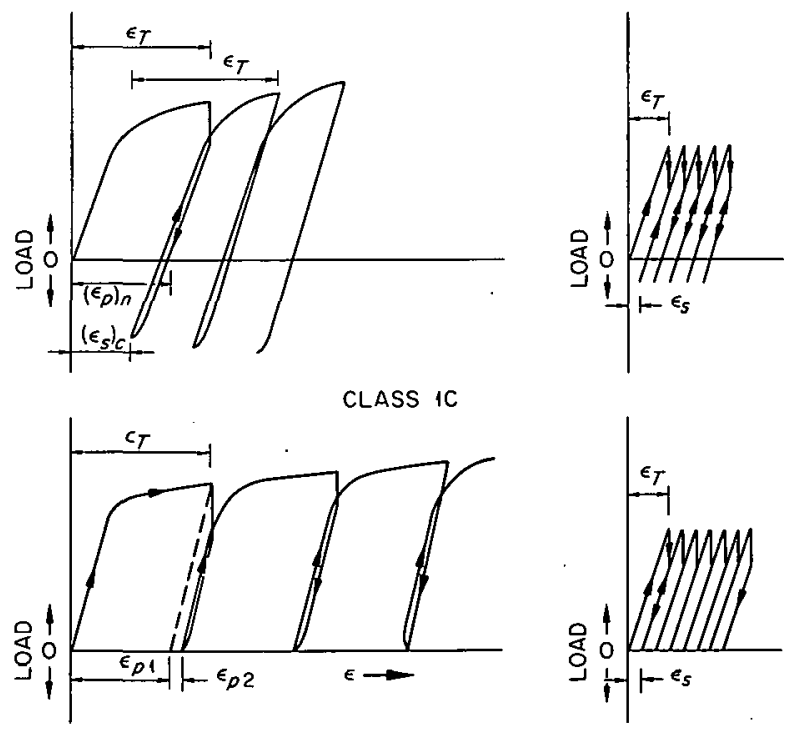

Fig. 5. Load-Extension Curves for Metal-Clad Fuel Elements During Thermal Cycling. 


\section{CONCLUSTONS}

The effect of pressure and cladding thickness on the behavior of stainless steel-clad uranium dioxide fuel elements during thermal cycling has been investigated. The plastic strain per thermal cycle increased when either the pressure was increased or the cladding thickness decreased. The experimental data have been analyzed and a model proposed for the observed behavior.

The model indicates several avenues of approach to decrease the magnitude of cladding strain.

1. Decrease the magnitude of thermal cycles.

2. Decrease the magnitude of total plastic strain by decreasing the number of thermal cycles.

3. For high-heat-rated elements, in which the thermal expansion of the fuel exceeds the expansion of the cladding, reduce the rate of reactor startup to minimize the difference in expansion.

4. For low-heat-rated elements, in which the thermal expansion of the cladding exceeds the expansion of the fuel, reduce the rate of reactor cooling after the cladding has been collapsed about the fuel to minimize the difference in contraction.

5. Decrease the contact pressure between fuel and cladding (decrease pressure differential).

6. Decrease the static coefficient of friction between cladding and fuel, possibly with lubricants.

7. Decrease the pellet length. :

There are, of course, possibilities of altering properties of the materials in order to reduce the severity of the problem. In this respect, the following would be beneficial.

1. Increase the proportional limit and yield strength of the cladding.

2. Increase the fatigue strength of the cladding.

3. Increase the cladding ductility so it can withstand plastic strains.

4. Decrease the elastic moduli and thermal expansion of the fuel for the temperature range in which the cladding operates. 
5. Increase the pellet fracture strength.

6. Improve the fracture characteristics of the fuel to eliminate fuel degradation and thus decrease frictional forces between fuel and cladding.

\section{ACKNOWLEDGMENTS}

The author wishes to acknowledge F. L. Beeler and E. Bolling for their assistance in conducting the experiments, J. R. Weir for his technical assistance in the data analyses, and Sigfred Peterson for assistance in the revision of the manuscript. 


\section{APPENDIX A}

Relaxation Model Relating Maximum Axial Cladding Stress to Plastic Strain Per Cycle

\section{Calculation from Creep Constants}

If one can estimate the total strain $\epsilon_{t}$ from extension-time plots such as in Fig. 3, the initial stress the cladding had been subjected to may be read from the stress-strain curve (Fig. 6) for the cladding material at the deformation temperature. From this stress, the plastic strain per cycle can then be calculated by the relationship derived by Kennedy and Douglas ${ }^{12}$ from Kanter's ${ }^{13}$ correlation of creep and relaxation:

$$
\epsilon_{p}=\frac{1}{E}\left[\sigma_{0}-\left(\frac{t E(n-1)}{A^{n}}+\sigma_{0}(1-n)\right)^{1 /(1-n)}\right]
$$

where

$$
\begin{aligned}
\epsilon_{\mathrm{p}} & =\text { plastic strain per cycle, } \\
\mathrm{E} & =\text { elastic modulus of the cladding, } \\
\sigma_{0} & =\text { maximum or initial stress, } \\
t & =\text { time in hours, and } \\
\mathrm{n}, \mathrm{A} & =\text { creep constants. }
\end{aligned}
$$

Using Kennedy: s $^{1.4}$ vailues for the creep consțants,

\begin{tabular}{clll}
$\begin{array}{c}\text { Temperature } \\
\left({ }^{\circ} \mathrm{F}\right)\end{array}$ & $\frac{\mathrm{n}}{6}$ & $\frac{\mathrm{A}}{73,200}$ \\
\hline 1200 & & 6 & \\
1300 & & 6 & 44,400 \\
1400 & 6 & 29,300 \\
1500 & 6 & 21,300 \\
1600 & 5.8 & 15,000
\end{tabular}

${ }^{12}$ C. R. Kennedy and D. A. Douglas, Relaxation Characteristics of Inconel at Elevated Temperatures; ORNL-2407 (Jan. 1960).

${ }^{13} \mathrm{~J}$. J. Kanter, "Interpretation and Use of Creep Results," Trans. Am. Soc. Metals 24, 900 (Dec. 1936).

14 Personal communication between W. R. Martin and C. R. Kennedy, May, 1963. 
one may calculate the approximate plastic strain per cycle as a function of hold time.

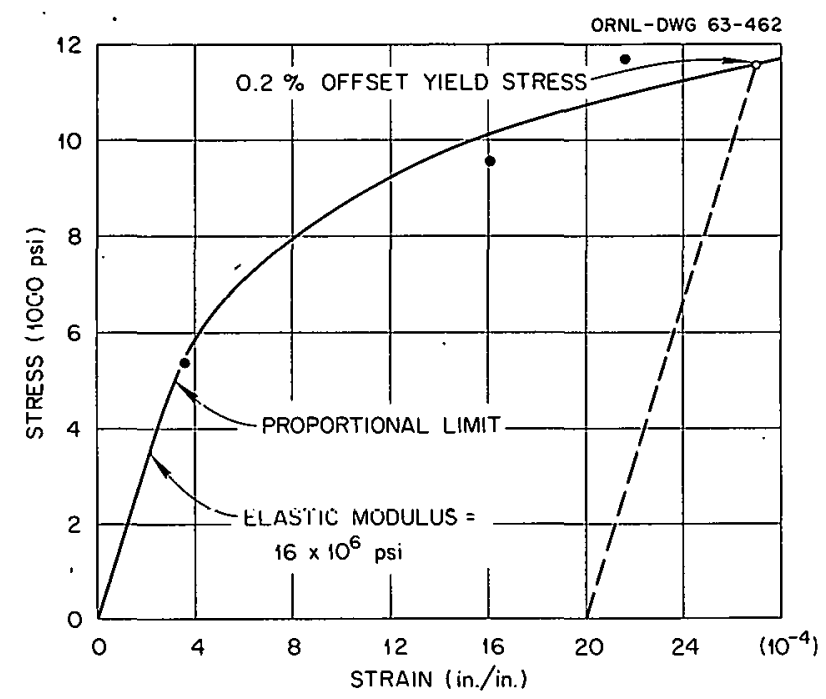

Fig. 6. Stress-Strain Curve of Type 304 Stainless Steel at $1475^{\circ} \mathrm{F}$.

\section{Graphical Calculation}

The plastic strain per cycle $\epsilon_{p}$ can be determined more easily with the stress relaxation plots given in Fig. 7. This quantity is given by:

$$
\epsilon_{\mathrm{p}}=\left(\sigma_{0}-\sigma\right) / \mathrm{E}
$$

where $\sigma$ is the stress in the clad at any time. For example, let us assume that the total strain was observed to be $2.2 \times 10^{-3}$. From Fig. 6 the initial stress is $11,000 \mathrm{psi}$. If the hold time at $1475^{\circ} \mathrm{F}$ is $0.5 \mathrm{hr}$, from Fig. 7 the final stress is 5000 psi. Substituting in the equation, we obtain for $\epsilon_{p}$

$$
\frac{11,000-5000}{16 \times 10^{6}}=3.8 \times 10^{-4} \text {. }
$$




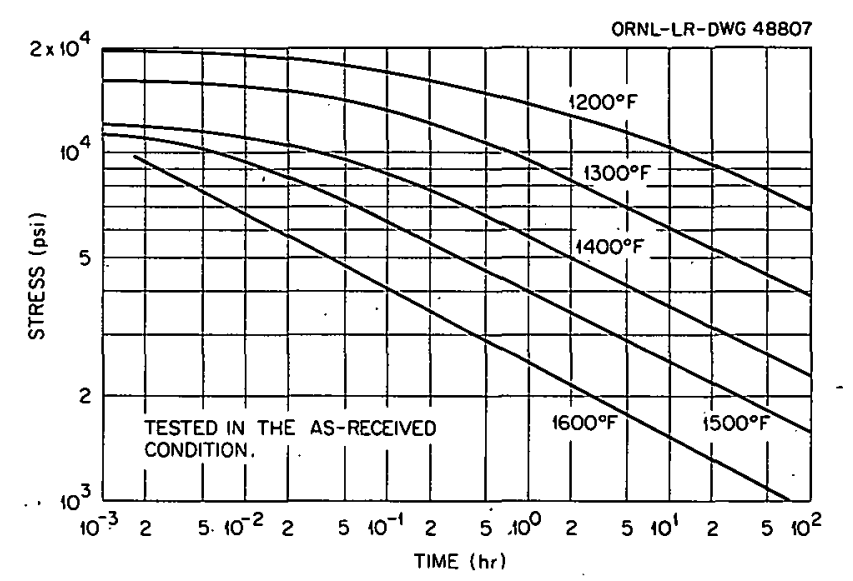

Fig. 7. Relaxation Characteristics of Type 304 Stainless Steel.

Calculation of $\epsilon_{t}$ from $\epsilon_{p}$

One experimentally observes the value of $\epsilon_{p}$. The amplitude of stress necessary to produce the strain $\epsilon_{p}$ is

$$
\Delta \sigma=\sigma_{0}-\sigma=\epsilon_{p} E
$$

where $\sigma_{0}$ is the stress at time zero and $\Delta \sigma$ is the stress at time necessary to produce $\epsilon_{\mathrm{p}}$.

Therefore, $\sigma_{0}=\Delta \sigma+\sigma=\epsilon_{p} E+\sigma$.

It has been experimentally determined that at a given time the maximum stress in the cladding will be as given in the stress relaxation plot (Fig. 7). Hence, knowing the time for which cladding is at a given temperature and the stress relaxation properties, one can determine $\sigma$.

For the conditions stated above, $\epsilon_{p}=3.8 \times 10^{-4}$ and $t=0.5 \mathrm{hr}$. Therefore,

$$
\begin{aligned}
& \sigma_{0}=6000+5000 \\
& \sigma_{0}=11,000 \text { psi. }
\end{aligned}
$$

Hence one can obtain $\epsilon_{t}$ from Fig. 6 , since $\sigma_{0}$ is known. One can also calculate $\epsilon_{p}$ for any given hold time for the same $\sigma_{0}$ and cladding temperature, as discussed previously. 


\section{APPENDIX B}

\section{Determination of Static Coefficients of Friction}

We have measured static coefficients of friction as a function of temperature for type 304 stainless steel in contact with sintered uranium dioxide fuel pellets. We have used a gravity loading method, in which the fuel tube was tilted until movement was detected. The angle of tilt $\theta$ at which sliding was detected was related to the coefficient of friction $\mu_{\mathrm{S}}$ by $\mu_{\mathrm{s}}=\tan \theta$.

Since the method is quite sensitive to vibration, the data are subject to considerable error. ${ }^{15}$ However, the fuel pellet is reasonably heavy (39 g), compared to the 2-to 5 -g metallic specimens to which this method has been applied. Therefore, the simplicity of the technique of measurement warranted this experimental approach to determine the coefficient between these two materials in the absence of high contact pressure.

The equipment is shown in Fig. 8. The coefficient was determined for several pellets in a partial vacuum $(<1 \mu)$ and in helium at 15 psi. The data for the temperature range of 20 to $900^{\circ} \mathrm{C}$ are given in Fig. 9 and Fig. 10. The temperature dependence of the data seems to be similar to that of other friction data. ${ }^{16}$ Before these measurements can be considered reliable, they should be repeated by a different experimental technique and extended to include the dependence on contact pressure.

${ }^{15}$ F. B. Bowden and D. Tabor, Friction and Lubrication, Wiley, Inndnn (1956) .

${ }^{16}$ E. Rabinowicz and M. Imai, Friction and Wear at Elevated Temperatures, WADC-TR-59-603, Part III (1962). 


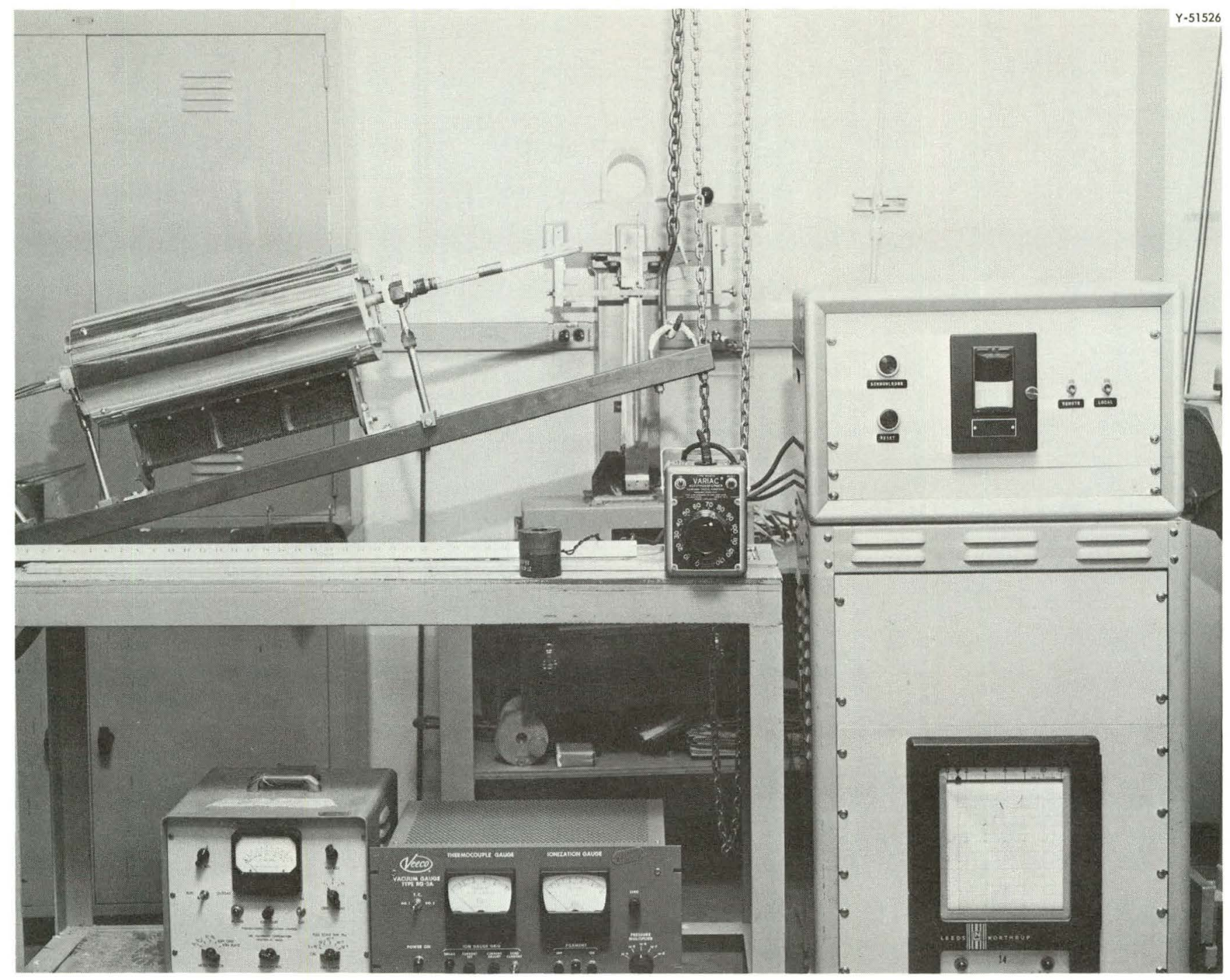

Fig. 8. Photograph of Device for Measurement of Static Coefficient of Friction at Elevated Temperatures in Controlled Environments. 


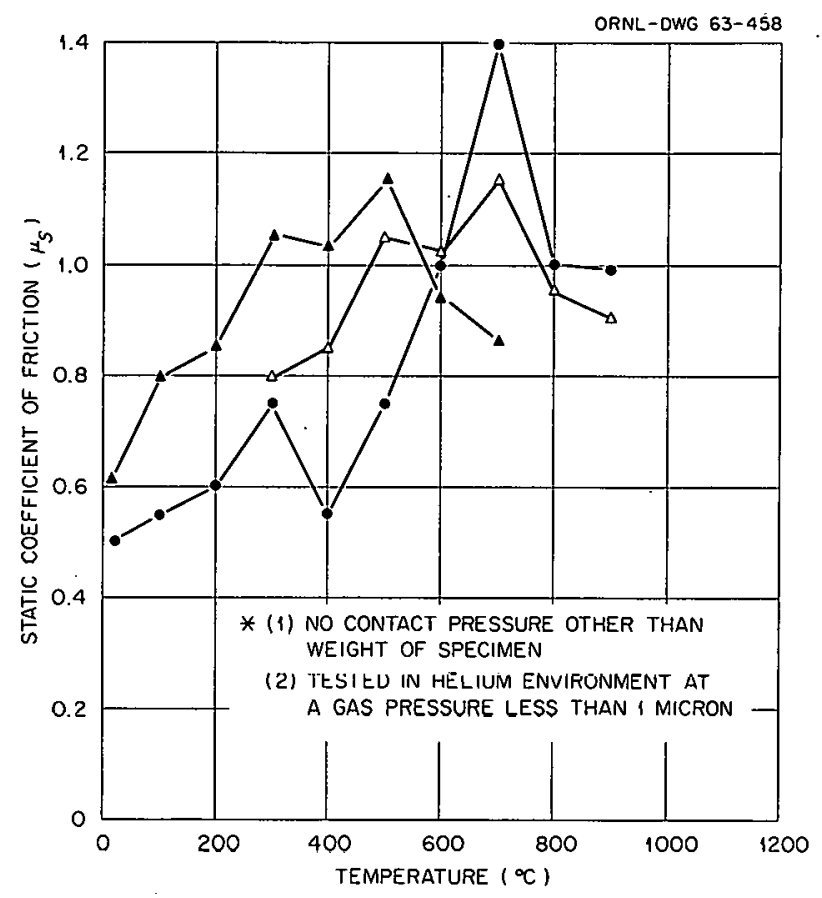

Fig. 9. Static Coefficient of Friction for $\mathrm{UO}_{2}$ and Stainless Etecl. Experiments with three different specimens are shown.

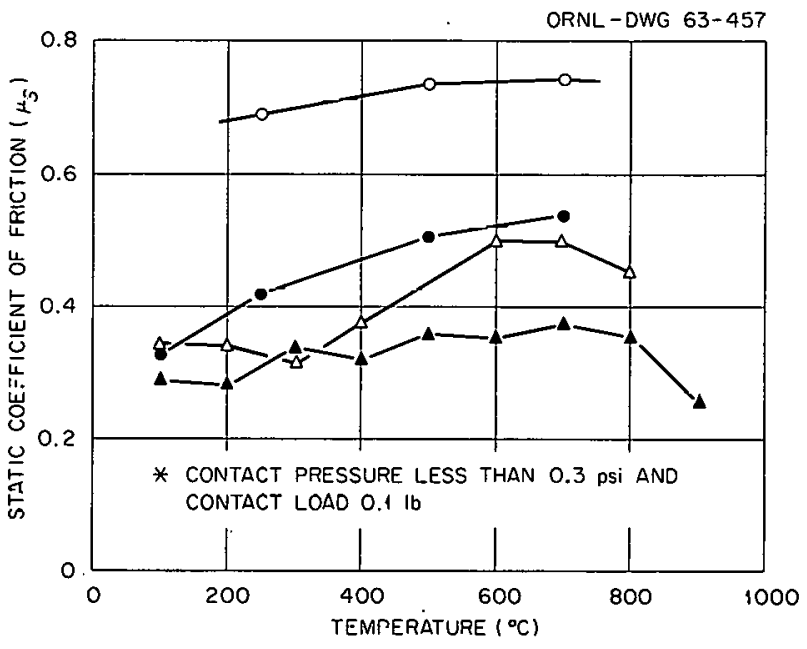

Fig. 10. Static Coefficient of Friction Between $\mathrm{UO}_{2}$ and Stainless Steel Tested in Helium at 15.0 psi. Experiments with three different specimens are shown. 


\section{THIS PAGE}

WAS INTENTIIONALLY

LEFT BLANK . 
ORNL-3514

UC-25 - Metals, Ceramics, and Materials TID-4500 (37th ed.)

\section{INTERNAL DISTRIBUTION}

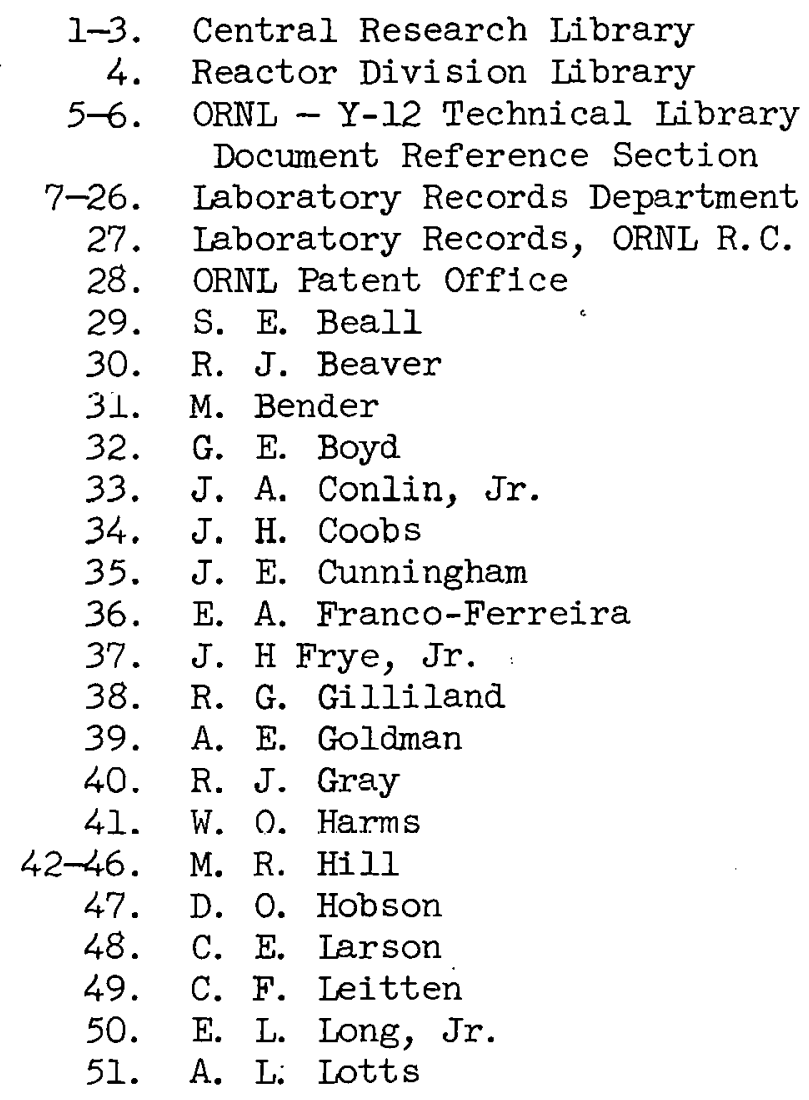

\section{EXTERNAL DISTRIBUTION}

106. C. M. Adams, Jr., Massachusetts Institute of Technology

107. I. V. Loburn, lenera $\perp$ Atomic

108-109. D. F. Cope, AEC, Oak Ridge Operations Office

110. G. B. Greenough, Atomic Energy Research Establishment, Springfield Works, England

111. J. L. Gregg, Bard Hall, Cornell University

112. A. Harvey, Atomic Energy of Canada Limited, Chalk Rïver

1.1.3. R. F. Kirkpatrick, AEC, Washington

114. M. J. F. Notley, Atomic Energy of Canada Limited, Chalk River

115. R. E. Pahler, AEC, Washington

116. S. Kabin, General Electric Company, San Jose

117. C. Ringot, Centre d'Etudes Nucleaires de Saclay, Saclay, France

118. F. Rough, Battelle Memorial Institute

119. M. Rozenholc, Centre d' Etudes Nucleaires de Saclay, Saclay, France

120. J. M. Siltanen, General Atonic 
121-123. J. Simmons, AEC, Washington

124. R. D. Stacey, Atomic Energy Research Establishment, Springfield Works, England

125. E. E. Stansbury, University of Tennessee

126. Donald K. Stevens, AEC, Washington

127. Division of Research and Development, AEC, Oak Ridge Operations

128-714. Given distribution as shown in TID-4500 (37th ed.) under Metals, Ceramics, and Materials Category ( 75 copies - CFSTI) 